\title{
Spatio-temporal distribution of eggs and larvae of half-fin anchovy Setipinna taty (Valenciennes, 1848) in the inshore waters off Jiangsu, China
}

\author{
YAN JIN, ZUN-LEI LIU, JIAN-HUA TANG* AND YONG LIU \\ East China Sea Fisheries Research Institute, Chinese Academy of Fishery Science, Shanghai - 200 090, China \\ "Marine Fisheries Research Institute of Jiangsu Province, Nantong - 226 007, China \\ e-mail: annidy@163.com
}

\begin{abstract}
Understanding the spatial distribution and environmental characteristics of fish spawning grounds is essential to design effective fishery management. The half-fin anchovy Setipinna taty (Valenciennes, 1848) plays an important role in the marine food web. A survey with 54 stations was conducted in 2014 to study the spatio-temporal distribution of eggs and larvae of half-fin anchovy around the inshore waters of Jiangsu, China. Half-fin anchovy eggs, larvae and juveniles were collected every month from April to July 2014. Generalised additive models were used to investigate the relationship between distribution of eggs, larvae and juveniles and environmental variables. A total of 4150 eggs and 685 half-fin anchovy larvae and juveniles were caught during the survey. During the spawning season, the highest egg densities were located in the inshore water area $\left(121^{\circ}-122^{\circ} \mathrm{E}, 32.5-33.5^{\circ} \mathrm{N}\right)$, with no significant shift in location of egg densities through time. The distribution of larvae and juveniles mostly overlapped with the egg distribution, suggesting that the early life stage of half-fin anchovy are distributed within the inshore waters of Jiangsu. The optimal water temperature, salinity and depth for eggs and larvae were in the range of $14.0-24.6^{\circ} \mathrm{C}, 28.7-29.8 \%$ and $15.9-17.4 \mathrm{~m}$, respectively.
\end{abstract}

Keywords: Distribution, Early life stages, GAM, Half-fin anchovy, Spawning ground

\section{Introduction}

There is increasing reliance on seafood these days, as human demand for animal protein is unlikely to be met by terrestrial farming. With many fisheries collapsing under high fishing effort, ensuring sustainability in fisheries has been a major public concern in recent years. A number of mechanisms may affect the population structure of fish, including lifelong behavioural effects such as accurate homing to the natal spawning area (Robichaud and Rose, 2004) and also short-term mechanisms operating within a specific spawning season. Monitoring fish spawning and nursery grounds is known to be the key step of an ecosystem-based approach for marine fisheries management (Lelievre et al., 2014; Paradinas et al., 2015) and also contributes to understand the biological processes (Espeland et al., 2007).

Half-fin anchovy Setipinna taty (Valenciennes, 1848) (Family Engraulidae), is a commercially important small fish in the coastal waters of China, which is also wildly distributed in the Indian Ocean and western Pacific Ocean (Cheng, 2006). Besides the characteristics of rapid growth, faster reproduction and high abundance, it also plays an important role in marine food web as it mainly feeds on zooplankton and is also the prey for medium or large fishes (Wang, 2013). With the regression of traditional commercially valuable demersal fishes, the economic value of half-fin anchovy has gradually increased (Jin, 2004). It has now become the main bycatch species and accounted for a non-meagre proportion of the total catch (Cheng et al., 2000; Zhang et al., 2006). Stock assessments indicated that the stock of half-fin anchovy in East China Sea has been severely overfished (Liu et al., 2006a). Thus there is an urgent need to develop a sustainable fishery management plan for this species.

Half-fin anchovy distribution has been reported from Bohai Sea and East China Sea (Liu et al., 2004, 2006b); however, there are no reports on the distribution of larvae and juveniles of this species which is essential for its management. Earlier studies have speculated that the inshore waters of Jiangsu was an important natural habitat for half-fin anchovy (Zhang et al., 2007). The inshore waters of Jiangsu form an important fishing ground for the coastal community. Affected by the northern Jiangsu coastal current and run-off from the Yangtze River and Huaihe River, this area is a zone between freshwater and seawater, which has led to its special ecological function and increased abundance of resources (Wang, 2003). However, limited information of early-life stages of half-fin anchovy in inshore waters of Jiangsu prevents characterisation of the mechanisms affecting half-fin anchovy distribution, including the possible influence of 
environmental factors during important life-cycle stages. Hence the present study was carried out to know the spatio-temporal distribution of early-life stages of halffin anchovy in Jiangsu and to illustrate the relationship between its distribution and environmental factors.

\section{Materials and methods}

Fishing surveys were carried out in the inshore waters of Jiangsu (Fig. 1). Fifty-four stations located along 4 transects $\left(1^{\circ}\right.$ apart) were surveyed. The stations were situated from the Fishing Prohibition zone line for motor trawler to the coast, with depth $>3 \mathrm{~m}$ at latitudes of $34.5^{\circ} \mathrm{N}(\mathrm{A}), 33.5^{\circ} \mathrm{N}$ (B), $32.5^{\circ} \mathrm{N}$ (C) and $31.5^{\circ} \mathrm{N}$ (D) around the inshore waters of Jiangsu. Survey was carried out every month from April to July 2014 during the breeding season (Zhang et al., 1994). Plankton nets (1.3 $\mathrm{m}$ dia, $6 \mathrm{~m}$ length and $0.5 \mathrm{~mm}$ mesh) were used to catch ichthyoplankton, since it has been reported that egg diameter of half-fin anchovy is above $0.5 \mathrm{~mm}$ (Petitgas et al., 2004). Each net was equipped with a flow-meter to estimate the water volume sampled. Horizontal tows of 10 min duration were made at a vessel speed of 1-2 knots. Additionally, temperature and salinity measurements were taken at all stations with a Seabird 37 CTD.

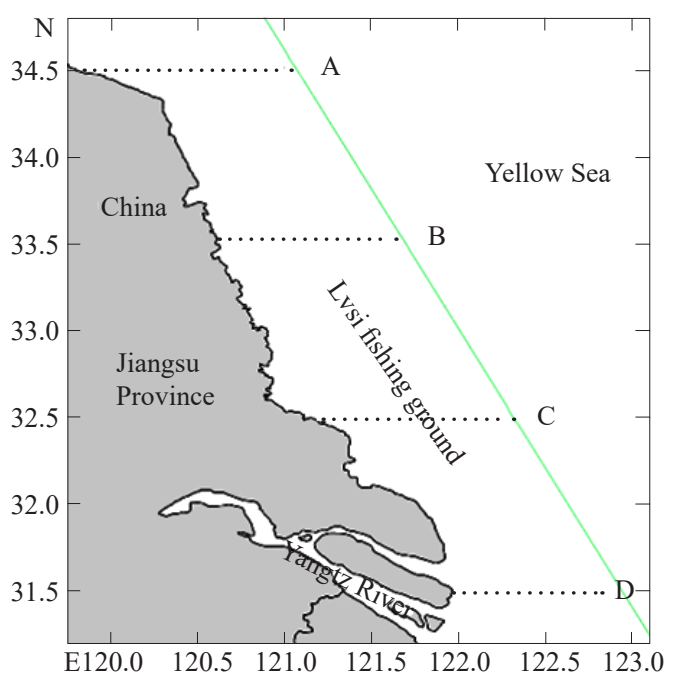

Fig. 1. Survey stations $(n=54)$ located along 4 transects (A, B, C, D) in inshore waters of Jiangsu

Samples were preserved immediately on collection using $5 \%$ formalin in seawater. In the laboratory, eggs and larvae were subsequently sorted following Wan and Jiang (2000) and Miller and Kendall (2009), counted and their abundance was standardised to numbers per $100 \mathrm{~m}^{3}$. The individuals of half-fin anchovy larvae were classified into different developmental stages (Miller and Kendall, 2009). Maps of salinity, temperature, depth, fish eggs and larvae were plotted in R.3.4.1.
The effects of environmental conditions, on the distribution of half-fin anchovy eggs and larvae around the waters of Jiangsu were examined using Generalised Additive Models (GAMs) (Guisan et al., 2002). We used the 'mgcv' package (Wood, 2011) of the R environment to implement the GAMs. GAMs are known to be less restrictive in assumptions about the underlying distribution of data, as it is a nonparametric generalisation of multiple linear regression (Hastie and Tibshirani, 1990). In the present study, we assumed a Poisson distribution (Jones et al., 2002). The environmental parameters and the fishing locations were modelled as independent variables. Hence, five variables were included in the analysis: Month, location (latitude and longitude), salinity, temperature and depth. Among them, except month, all were continuous variables. The GAM model was of the form:

$$
\text { In (abundance }+0.01)=\mathrm{a}+\sum_{\mathrm{j}=1}^{\mathrm{n}} f_{\mathrm{i}}\left(\mathrm{x}_{\mathrm{i}}\right)+\varepsilon
$$

where, $a$ is a constant, $f_{\mathrm{i}}\left(\mathrm{x}_{\mathrm{j}}\right)$ is the spline smoother function of the corresponding independent variable, including month, location, salinity, temperature and depth and $\varepsilon$ is a random error term. Significant levels for the added predictors were estimated by means of the $F$ test and the level of significance was set at $95 \%$. The Akaike Information Criterion (AIC) was used to detect the relative importance of each variable in explaining variation. The AIC statistic accounts simultaneously for the degrees of freedom used and the goodness of fit; a smaller AIC statistic corresponds to a better model in the sense of smaller residual deviance penalised by the number of parameters that are estimated in fitting the model.

\section{Results and discussion}

The surveys indicated that there were spatial and temporal differences in the distribution of half-fin anchovy eggs and larvae in the inshore waters of Jiangsu. As shown in Fig. 2 A, during May to July, the half-fin anchovy eggs were mainly distributed along transects $\mathrm{B}$ and $\mathrm{C}$, with sporadic occurrence in transect A. Along transect D, neither egg nor fish were found throughout 4 months. In the present study, the greatest egg densities were in the inshore water area, with no significant shift in location of egg distribution through time $\left(33.5^{\circ}-32.5^{\circ} \mathrm{N}, 121^{\circ}-122^{\circ} \mathrm{E}\right)$, but the peak egg densities slightly shifted from north to south. In addition, the distribution of larvae and juveniles were mostly overlapping with the egg distribution, with only a weak shift all around. Thus, we concluded that the inshore waters of Jiangsu $\left(32.5^{\circ}-33.5^{\circ} \mathrm{N}\right)$ was a major spawning ground for half-fin anchovy. Based on the distribution of adult half-fin anchovy, Liu et al. (2004) put forward that half-fin anchovy along the China coast has two populations: northern East China Sea group 


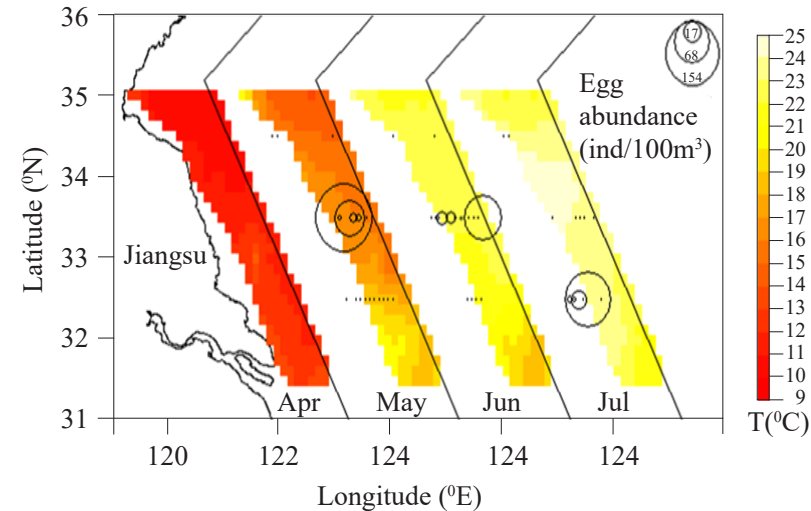

(A)

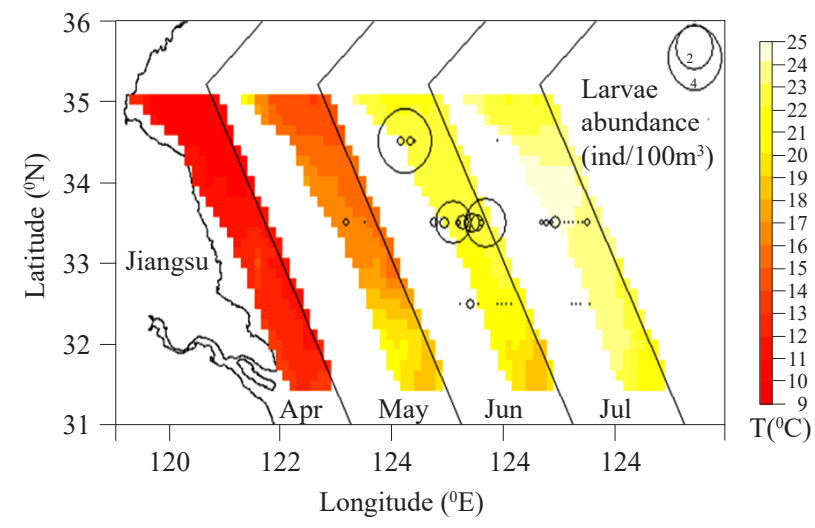

(C)

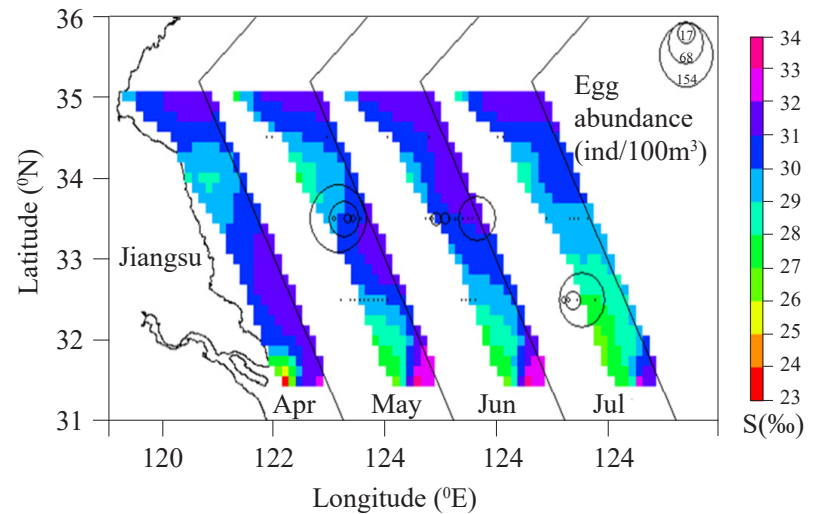

(B)

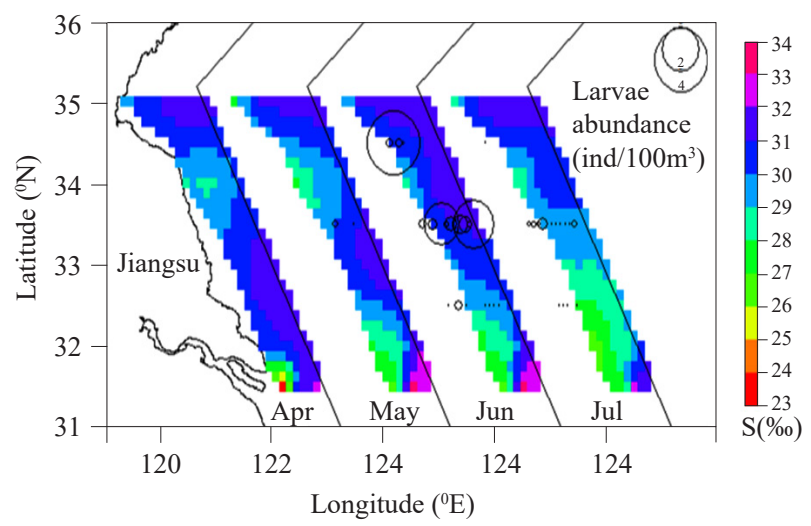

(D)

Fig. 2. Distributional patterns observed in inshore waters of Jiangsu during April to July in 2014. Abundance of half-fin anchovy eggs $(\mathrm{A}, \mathrm{B})$ and larvae $(\mathrm{C}, \mathrm{D})$. Temperature $(\mathrm{A}, \mathrm{C})$ and salinity $(\mathrm{B}, \mathrm{D})$ are represented by colours according to the vertical palette

and middle and southern East China Sea group. Thus, the present study likely demonstrated the most possible spawning ground of northern East China Sea group of half-fin anchovy.

The inshore distribution of eggs indicated inshore spawning activity and a temporal peak in egg densities, likely described the peak of the spawning season (Kjesbu, 1989). In the present study, 4150 half-fin anchovy eggs were collected during the survey. As shown in Fig. 3, there were no eggs in April, but in May it came into the ovipositing peak. The mean egg abundance in the sampling area (54 stations) in May reached 5.73 nos. $100 \mathrm{~m}^{-3}$, while in June and July, the mean egg abundance were 3.77 and 3.86 nos. $100 \mathrm{~m}^{-3}$, respectively.

A total of 685 half-fin anchovy larvae and juvenile fish were collected during the four sampling cycles. There was also no fish in April. In the other months (May to July), the mean abundance in all the sampling stations increased first and then decreased (Fig. 3) and the highest mean abundance of all sampling stations was 3.14 nos. $100 \mathrm{~m}^{-3}$ in June. For single sampling station, the highest abundance occurred in July with 126.3 nos. $100 \mathrm{~m}^{-3}$. The

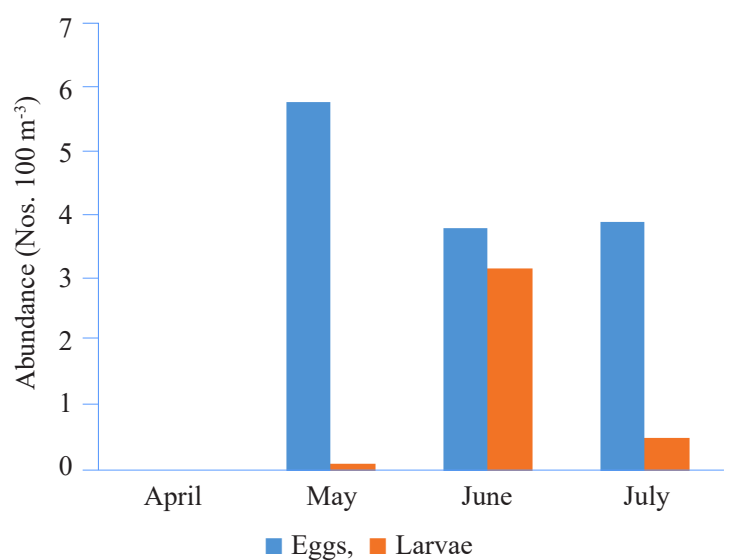

Fig. 3. Mean egg and larvae abundance in the sampling area (nos. $100 \mathrm{~m}^{-3}$ ) in different months during 2014

mean abundance and the occurrence of developmental stages varied between the four months (Fig. 4). In May, the half-fin anchovy started to spawn, sporadic pre-flexion larvae were observed in transect B near the coast. In June, only a few yolk-sac larvae were observed, pre-flexion and flexion larvae took up a large proportion, which accounted 


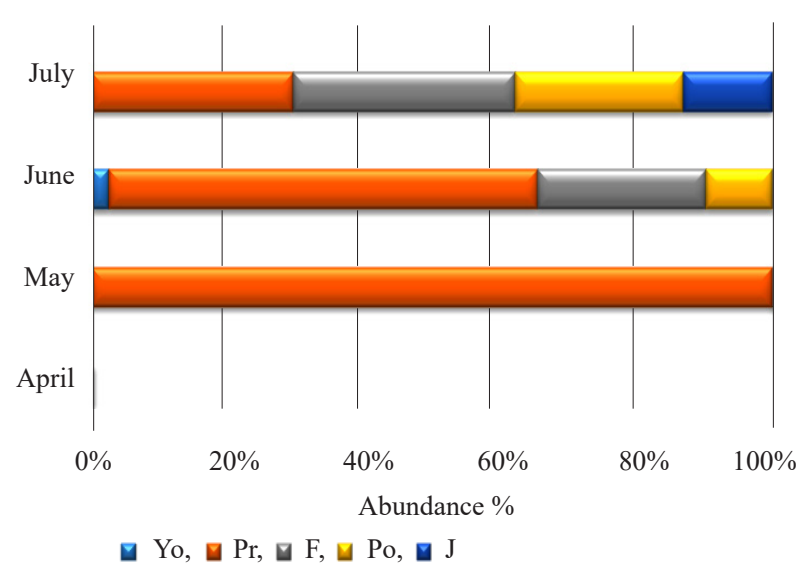

Fig. 4. Abundance (nos. $100 \mathrm{~m}^{-3}$ ) and proportion (\%) of different developmental stages in different months in 2014; Yo, Pre, F, Po and $J$ stand for yolk-sac, pre-flexion, flexion, post-flexion and juvenile, respectively

for 62.87 and $24.81 \%$, respectively. During July, flexion larvae $(32 \%)$ formed the majority of larvae collected, followed by pre- and post-flexion larvae.

According to the abundance of eggs and larvae in different months, the spawning season of half-fin anchovy was estimated to have started from early May and was thriving in late May and early June, which was slightly later than historical records of the Fisheries Bureau of the Ministry of Agriculture (1990). According to the historical records, with the increasing water temperature in March every year, wintering group of half-fin anchovy started their spawning migration. In middle March, they reached Yangtze Estuary and Lvsi fishing ground. In April, the spawning season started and the flourishing period was in late April and early May. After that, half-fin anchovy spread all over south of Yellow Sea, until November when they came back to the wintering ground (Fisheries Bureau of the Ministry of Agriculture, 1990).

Even slight change in biological characteristics of half-fin anchovy was reflected in the geographical distribution. The records in 1980s showed that half-fin anchovy had a large scale spawning ground in the inshore waters of Jiangsu, covered from Yangtze Estuary to the island of Cheniushan (Animal Husbandry and Fishery Bureau, 1987). Later, Zheng et al. (2003) reported that the distribution of half-fin anchovy in the four seasons were similar, mainly distributed in the Yangtze Estuary and to its north. With the seasonal migration seemingly not obvious anymore, it indicated that the distribution range of half-fin anchovy was significantly reduced. Liu et al. (2004) and Xiong et al. (2009) also reported reduction of distribution range of half-fin anchovy.
The stable distribution of eggs and larvae throughout the spawning season (May to July) in the present survey was indicative of inshore retention of the early life stages (Espeland et al., 2007) and revealed the possible migration strategies of the northern East China Sea group of half-fin anchovy. They were very likely to migrate along east-west direction and do not migrate south to across the mouth of the Yangtze River, as no eggs and larvae were observed along the transect D.

In the present study, the distributions of larvae and juveniles were mostly overlapping with the egg distribution, with only a weak shift all around. It suggested that the early life stage of half-fin anchovy was being retained around the inshore waters of Jiangsu. Although the swimming ability of adult half-fin anchovy has been reported to be low (Zhang et al., 2004), the distribution of eggs and larvae are controlled by both active behaviour and passive transport mechanisms (Santos et al., 2006).

The distribution of half-fin anchovy eggs and larvae in the present study might be associated with the special geographical conditions prevailing in the inshore areas of Jiangsu. First, spawning in inshore areas sheltered from strong currents could reduce passive drift of eggs and larvae and help to maintain local self-reproducing units (Hastings and Botsford, 2006). Second, the inshore area of Jiangsu has special radiating sand ridges, distributed between south of Sheyang and north of Yangtze River Estuary (Wang, 1988). This kind of landscape is an ideal place for half-fin anchovy, as it has been reported that half-fin anchovy prefers to inhabit in shallow seas with slower current and silt sediment (Cheng and Zhou, 1997). In the present study, the water depth in the sampling area ranged from 7.0 to $33.8 \mathrm{~m}$ and was nearly the same during the 4 months (Fig. 5). The lowest water depth where half-fin anchovy eggs and larvae were observed was

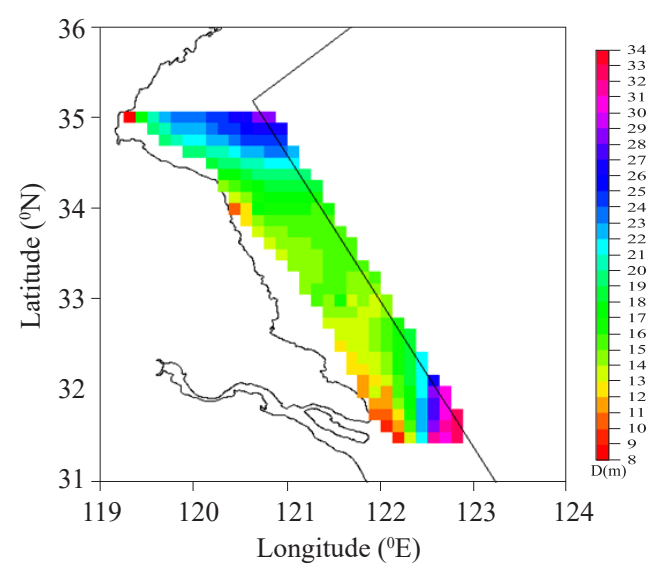

Fig. 5. Water depth (m) around the inshore waters of Jiangsu 
$10.4 \mathrm{~m}$, while the highest was $28.4 \mathrm{~m}$. However, eggs and larvae were mainly distributed in the depth range 15.9-17.5 $\mathrm{m}$. The GAM modelling also showed that depth effect was important for both eggs and larvae.

In the present study, all variables added to the egg models were significant $(\mathrm{p}<0.05)$ and resulted in lower AIC values (Table 1). The results showed that among all the variables, the depth effect was the most important variable ( $16.2 \%$ of explained deviance), followed by the effect of month and geographic location, which accounted for 14.2 and $13.4 \%$ of explained deviance, respectively, whereas the temperature effect explained only $8.4 \%$.

Similarly, all variables added to the analysis of deviance in larvae models were significant $(\mathrm{p}<0.05)$ and resulted in greater resolving power with lower AIC values (Table 2). According to the percentage deviance explained, month and location were the most important factors. The inclusion of other variables (depth and temperature) in this

Table 1. Deviance analysis in the GAM models of half-fin anchovy eggs in the inshore waters of Jiangsu in 2014

\begin{tabular}{|c|c|c|c|c|c|c|c|}
\hline \multicolumn{8}{|c|}{ Variable selection } \\
\hline Eggs & Resid.df & df & Resid. Dev & Deviance & $\mathrm{p}$ & Dev. Expl (\%) & AIC \\
\hline NULL & 176 & & 1000.02 & & $<0.01$ & 0 & 812.8 \\
\hline Month & 173 & 3 & 857.92 & 142.09 & & 14.2 & 791.68 \\
\hline May & & & & & $<0.01$ & & \\
\hline June & & & & & $<0.01$ & & \\
\hline July & & & & & 0.03 & & \\
\hline S (Long., Lat.) & 159.88 & 16.12 & 539.72 & 460.29 & $<0.01$ & 46 & 735.89 \\
\hline S (Salinity) & 173.54 & 2.46 & 961.85 & 38.17 & 0.193 & 3.82 & 810.84 \\
\hline S (Depth) & 172.13 & 3.87 & 842.56 & 157.45 & $<0.01$ & 15.7 & 790.21 \\
\hline S (Temperture) & 168 & 7.99 & 650.24 & 349.78 & $<0.01$ & 35 & 752.6 \\
\hline \multicolumn{8}{|l|}{ Model selection } \\
\hline+ Month & 173 & 3 & 857.92 & 142.09 & & 14.2 & 791.67 \\
\hline +s (Depth) & 166.7 & 6.3 & 695.79 & 162.13 & & 30.4 & 767.2 \\
\hline$+\mathrm{s}$ (Temperature) & 163.8 & 2.9 & 611.77 & 84.03 & & 38.8 & 750.21 \\
\hline +s (Long., Lat.) & 153.52 & 10.28 & 477.88 & 133.89 & & 52.2 & 727.05 \\
\hline
\end{tabular}

Resid. df - Residual degrees of freedom; df - Degrees of freedom; Resid. Dev. - Residual deviance; P - F test p value; Dev.expl. (\%) - Explained deviance by each model; AIC - Akaike information criterion

Table 2. Deviance analysis in the GAM models of half-fin anchovy larvae in the inshore waters of Jiangsu in 2014

\begin{tabular}{|c|c|c|c|c|c|c|c|}
\hline \multicolumn{8}{|c|}{ Variable selection } \\
\hline Larvae & Resid. df & df & Resid. Dev & Deviance & $\mathrm{P}$ & Dev. Expl (\%) & $\mathrm{AIC}$ \\
\hline NULL & 176 & & 774.19 & 0 & $<0.01$ & 0 & 767.5 \\
\hline Month & 173 & 3 & 614.75 & 159.44 & & 20.6 & 732.68 \\
\hline May & & & & & 0.55 & & \\
\hline June & & & & & $<0.01$ & & \\
\hline July & & & & & $<0.01$ & & \\
\hline s (Long., Lat.) & 163.75 & 12.25 & 527.31 & 246.88 & $<0.01$ & 31.9 & 724.03 \\
\hline s (Salinity) & 174.7 & 1.3 & 770.34 & 3.85 & 0.74 & 0.5 & 769.21 \\
\hline s (Depth) & 173.85 & 2.15 & 733.04 & 41.15 & 0.03 & 5.32 & 762.12 \\
\hline s (Temperature) & 172.36 & 3.64 & 518.93 & 255.26 & $<0.01$ & 33 & 707.97 \\
\hline \multicolumn{8}{|l|}{ Model selection } \\
\hline$+\mathrm{s}$ (Depth) & 173.85 & 2.15 & 733.04 & 41.15 & & 5.32 & 762.12 \\
\hline+ Month & 170.85 & 3 & 563.79 & 169.24 & & 27.2 & 721.67 \\
\hline +s (Long., Lat.) & 161.98 & 8.87 & 437.65 & 126.14 & & 43.5 & 694.58 \\
\hline +s (Temperature) & 161.59 & 0.39 & 366.52 & 71.14 & & 52.7 & 663.96 \\
\hline
\end{tabular}

Resid. df - Residual degrees of freedom; df - Degrees of freedom; Resid. Dev. - Residual deviance; P - F test p value; Dev.expl. (\%) - Explained deviance by each model; AIC - Akaike information criterion 
model also caused decrease of residual deviance, but these variables had much lower explanatory power (Table 2). The salinity effect was not significant either in egg models or larvae models.

Based on the results of GAM modelling, water temperature and salinity also contributed to the egg and larvae distribution. Ample evidences have shown that the change of seawater temperature not only has important impacts on the geographic distribution of fishes (Stenseth et al., 2002; Beaugrand, 2009; Sabates et al., 2012), but also can affect the behaviour of fish spawning and migration (Edwards and Richardson, 2004; Jansen and Gislason, 2011). As Whitfield and Pattrick (2015) pointed out that an ideal habitat to serve as a nursery or spawning ground must have several characteristics viz., (a) be physiologically suitable in terms of chemical and physical features; (b) have connectivity to enable colonisation by larvae and/or early juveniles; (c) provide abundant and suitable food and (d) afford a degree of protection from predators. Among these characteristics, physical features are especially important (Vastano et al., 1992).

The water temperature increased sharply in the sampling area from April to July and the water temperature near the Fishing Prohibition zone line was slightly lower than the coastal water temperature (Fig. 2). Affected by the northern Jiangsu coastal current and runoff from Yangtze River and Huaihe River, the salinity during the 4 months ranged from 27.5 to $32.0 \%$ (Fig. 2). Generally, the coastal water salinities were lower than that in the outside water area. A high temperature and low salinity water area is present in the north-east of $33^{\circ} \mathrm{N}, 121^{\circ} \mathrm{E}$.

As shown in Fig. 2, when the water temperature was below $14^{\circ} \mathrm{C}$, no eggs were observed in the sampling area in April. Till May, with the increasing water temperature, sporadic eggs of half-fin anchovy were found in the north and most of the eggs were concentrated in the area with $15-17^{\circ} \mathrm{C}$ water temperature. During June and July, the eggs were distributed mainly in the area under $24^{\circ} \mathrm{C}$. Through the whole sampling period, the water temperature in the area where half-fin anchovy eggs were distributed ranged from $14.0-24.6^{\circ} \mathrm{C}$ and the optimal water temperature ranged from $15.4-23.4^{\circ} \mathrm{C}$. This was in accordance with the studies on the parent fish. Previous studies showed that the temperature ranges were $15-27.1^{\circ} \mathrm{C}$ in the area where mature half-fin anchovy were distributed (Zhang et al., 1994). These results pointed out that half-fin anchovy larvae cannot be found in temperatures lower than $14^{\circ} \mathrm{C}$. Taking the results of GAM modelling, half-fin anchovy early life stages were found sensitive to temperature, though there was more than 10 degrees variation in the area where eggs and larvae were distributed. However, the distribution of eggs and larvae was not sensitive to water salinity, as the optimal salinity for mature fish was 28.98-32.14\%o (Zhang et al., 1994) and for eggs and larvae was $28.7-29.8 \%$. In the present study, most of the half-fin anchovy eggs were distributed around the relatively low salinity water area (28.7$29.8 \%$ o). During May to July, the lowest salinity where half-fin anchovy eggs were distributed was $28.1 \%$, while the highest was $31.7 \%$. The larvae and juveniles nearly followed the same ecological habit as eggs.

Our results have two important implications for the assessment and management of half-fin anchovy in the study area. First, half-fin anchovy along the China coast could be divided into two groups. The northern East China Sea group of half-fin anchovy is very likely to migrate along east-west direction and do not migrate south to across the mouth of the Yangtze River. Second, the spawning season for northern East China Sea group is in May to July and the most possible spawning ground for this group is in the inshore water area $\left(121^{\circ}-122^{\circ} \mathrm{E}\right.$, $\left.32.5-33.5^{\circ} \mathrm{N}\right)$.

\section{Acknowledgements}

The study was funded by the Ministry of Agriculture Financial Project: Investigation of spawning grounds in the inshore water of East China Sea.

\section{References}

Animal Husbandry and Fishery Bureau 1987. Investigation and zoning of fishery resources in the East China Sea. East China Normal University Press, Shanghai.

Beaugrand, G. 2009. Decadal changes in climate and ecosystems in the North Atlantic ocean and adjacent seas. Deep Sea Res. Pt. II, 56(56): 656-673. DOI: 10.1016/j.dsr2.2008.12.022.

Cheng, J. H. 2006. Fisheries resources utilization in Yellow Sea and East China Sea. Shanghai Scientific and Technical Publishers, Shanghai.

Cheng, J. H., Chen, X. Z., Lin, L. S., Tang, J. H. and Liu, B. X. 2000. Dynamics analysis of abailable resource structure for stow net fisheries in East China Sea region. J. Fish. Sci. China, 2: 64-68 (in Chinese with English abstract).

Cheng, Q. T. and Zhou, C. W. 1997. Fishes of Shangdong province. Shandong Technology Press, Jinan.

Edwards, M. and Richardson, A. J. 2004. Impact of climate change on marine pelagic phenology and trophic mismatch. Nature, 430(7002): 881-884. DOI: 10.1038/nature02808.

Espeland, S. H., Gundersen, A. F., Olsen, E. M., Knutsen, H., Gjosaeter, J. and Stenseth, N. C. 2007. Home range and elevated egg densities within an inshore spawning ground of coastal cod. ICES J. Mar. Sci., 64(5): 920-928. doi. org/10.1093/icesjms/fsm028. 
Fisheries Bureau of the Ministry of Agriculture 1990. Investigation and zoning of fishery resources in the Yellow Sea and Bohai Sea. Ocean Press, Beijing.

Guisan, A., Edwards, T. C. and Hastie, T. 2002. Generalised linear and generalised additive models in studies of species distributions: setting the scene. Ecol. Model., 157(2): 89-100. DOI: 10.1016/S0304-3800(02)00204-1.

Hastings, A. and Botsford, L. W. 2006. Persistence of spatial populations depends on returning home, Proc. Natl. Acad. Sci. USA, 103: 6067-6072. doi.org/10.1073/pnas.0506651 103.

Hastie, T. and Tibshirani, R. 1990. Generalised additive models $[M]$. John Wiley \& Sons, Inc.

Jansen, T. and Gislason, H. 2011. Temperature affects the timing of spawning and migration of North Sea mackerel. Cont. Shelf Res., 31(1): 64-72. DOI: 10.1016/j.csr.2010.11.003.

Jin, X. S. 2004. Long-term changes in fish community structure in the Bohai Sea. Estuar. Coast. Shelf Sci., 59(1): 163-171.

Jones, M. T., Niemi, G. J., Hanowski, J. M. and Regal, R. R. 2002. Poisson regression: a better approach to modeling abundance data. In: Scott, J. M., Heglund, P. J., Samson, F., Haufler, J., Morrison, M., Raphael, M., Wall, B. (Eds.). Predicting species occurrences: Issues of accuracy and scale. Island Press, Covelo, CA.

Kjesbu, O. S. 1989. The spawning activity of cod, Gadus morhua L. J. Fish Biol., 34: 195-206. doi.org/10.1111/j.1095-86 49.1989.tb03302.x.

Lelievre, S., Vaz, S., Martin, C. S. and Loots, C. 2014. Delineating recurrent fish spawning habitats in the North Sea. J. Sea Res., 91(8): 1-14. doi.org/10.1016/j.seares.2014.03.008.

Liu, Y., Cheng, J. H. and Chen, X. G. 2006a. Studies on the seasonal distribution of Setipinna taty in the East China Sea. Mar. Fish. Res., 27(3): 1-6 (in Chinese with English abstract).

Liu, Y., Cheng, J. H. and Li, S. F. 2004. A study on the distribution of Setipinna taty in the East China Sea. Mar. Fish., 26(4): 255-260 (in Chinese with English abstract).

Liu, Y., Cheng, J. H. and Li, S. F. 2006b. Utilisation status of Setipinna taty in the East China Sea and its rational exploitation. J. Fish. Sci. China, 3: 485-491 (in Chinese with English abstract).

Miller, B. S. and Kendall, A. W. J. 2009. Early life history of marine fishes. University of California Press, p. 45-46.

Paradinas, I., Conesa, D., Pennino, M. G., Munoz, F., Fernandez, A. M. and Lopez-Quilez, A. 2015. Bayesian spatio-temporal approach to identifying fish nurseries by validating persistence areas. Mar. Ecol. Prog. Ser., 528: 245-255. DOI.10.3354/meps11281.

Petitgas, P., Magri, S. and Lazure, P. A. 2004. One-dimensional model for the vertical distribution of fish eggs: sensitivity analysis and validation [J]. ICES CM 2004/P:34.
Robichaud, D. and Rose, G. A. 2004. Migratory behaviour and range in Atlantic cod: inference from a century of tagging, Fish Fish., 5: 185-214. doi.org/10.1111/j.1467-2679. 2004. 00141.x.

Sabates, A., Martin, P. and Raya, V. 2012. Changes in life-history traits in relation to climate change: bluefish (Pomatomus saltatrix) in the north-western Mediterranean. ICES J. Mar. Sci.,69(6): 1000-1009. DOI: 10.1093/icesjms/fss053.

Santos, A. M. P., Re, P., Santos, A. D. and Alvaro, P. 2006. Vertical distribution of the European sardine (Sardina pilchardus) larvae and its implications for their survival. J. Plankton Res., 28(5): 523-532. doi.org/10.1093/plankt/ fbi137.

Stenseth, N. C., Mysterud, A., Ottersen, G., Hurrell, J. W., Chan, K. S. and Lima, M. 2002. Ecological effects of climate fluctuations. Science, 297(5585): 1292-1296. DOI: 10.1126/science. 1071281 .

Vastano, A. C., Incze, L. S. and Schumacher, J. D. 1992. Observation and analysis of fishery processes: larval pollock at Shelikof Strait, Alaska. Fish. Oceanogr., 1(1): 20-31.

Wan, R. J. and Jiang, Y. W. 2000. The species and biological characteristics of the eggs and larvae of osteichthyes in the Bohai Sea and Yellow Sea. J. Shanghai Fish. Univ., 9(4): 290-297.

Wang, B. D. 2003. Nutrient distributions and their limitation on phytoplankton in the Yellow Sea and the East China Sea. J. Appl. Ecol., 14(7): 1122-1126 (in Chinese with English abstract).

Wang, T. T., Lv, Z. B., Li, F., Xu, B. Q., Zhang, A. B. and Zheng, L. 2013. Determination of the trophic levels of four fish species in Engraulidae and Clupeidae in Laizhou Bay based on stable carbon and nitrogen isotopes. J. Fish. Sci. China, 20(5): 1076-1085 (in Chinese with English abstract). doi. org/10.3724/sp.j.1118.2013.01076.

Wang, Y. S. 1988. The geomorphic development of radiating sand ridges in the Jiangsu seashore. Geogr. Res., 7(2): 41-49 (in Chinese with English abstract).

Whitfield, A. K. and Pattrick, P. 2015. Habitat type and nursery function for coastal marine fish species, with emphasis on the Eastern Cape region, South Africa. Estuar. Coast. Shelf Sci., 160: 49-59. doi.org/10.1016/j.ecss.2015.04.002.

Wood, S. N. 2011. mgcv: Mixed GAM Computation Vehicle with GCV/AIC/REML Smoothness Estimation. $R$ Package Version 1.7-6.

Xiong, Y., Tang, J. H., Liu, P. T., Zhong, X. M., Yan, L. P., Gao, Y. S., Wu, L. and Mao, H. 2009. Resource estimate on Setipinna taty in the southern Yellow sea. Oceanologia et Limnologia Sinica, 40(4): 500-505. (in Chinese with English abstract).

Zhang, Q. H., Cheng, J. H., Xu, H. X., Shen, X. Q., Yu, G. P. and Zheng, Y. J. 2007. Fisheries resources in East China 
Sea and its sustainable utilisation. Fudan University Press, Shanghai.

Zhang, P., Wang, Y. W. and Li, S. F. 2006. Fishes in Yangtze Estuary. Shanghai Scientific and Technical Publishers, Shanghai.

Zhang, M. H., Sun, T. Q., Li, Y. M., Guo, J. W. and Wang, X. F. 1994. Study on the seasonal distribution of sexually mature half-fin anchovy in Southern Bohai Sea. Trans. Oceanol. Limnol., 4: 72-80. (in Chinese with English abstract).
Zheng, Y. J., Chen, X. Z., Cheng, J. H., Wang, Y. L., Shen, X. Q., Chen, W. Z. and Li, C. S. 2003. Biological resources and environment of the East China sea shelf. Shanghai Scientific and Technical Publishers, Shanghai.

Zhang, J., Sun, M. C., Peng, Y. Z. and Qian, W. G. 2004. Study of the mesh selectivity of diamond and square mesh codend of two-stick swingnet. J. Shanghai Fish. Univ., 13(4): 328-334 (in Chinese with English abstract). 